\title{
Analysis of Flame Suppression Capabilities Using Low-Frequency Acoustic Waves and Frequency Sweeping Techniques
}

\author{
Jacek Łukasz Wilk-Jakubowski
}

check for

updates

Citation: Wilk-Jakubowski, J.Ł. Analysis of Flame Suppression Capabilities Using Low-Frequency Acoustic Waves and Frequency Sweeping Techniques. Symmetry 2021, 13, 1299. https://doi.org/10.3390/ sym13071299

\section{Academic Editors:}

Roumen Kountchev, Rumen Mironov and Kuo-Hui Yeh

Received: 12 May 2021

Accepted: 7 July 2021

Published: 19 July 2021

Publisher's Note: MDPI stays neutral with regard to jurisdictional claims in published maps and institutional affiliations.

Copyright: (C) 2021 by the author. Licensee MDPI, Basel, Switzerland. This article is an open access article distributed under the terms and conditions of the Creative Commons Attribution (CC BY) license (https:/ / creativecommons.org/licenses/by/ $4.0 /)$.
Department of Information Systems, Kielce University of Technology, 7 Tysiąclecia Państwa Polskiego Ave., 25-314 Kielce, Poland; j.wilk@tu.kielce.pl; Tel.: +48-41-342-42-01

\begin{abstract}
Symmetry plays a key role in the processing and analysis of not only visual but also acoustic signals in various multidisciplinary areas. New innovative and environmentally friendly methods for extinguishing flames are still being sought worldwide. One of these techniques appears to be the acoustic method. A laboratory stand was built for this purpose, which was coupled with the tested prototype of a high-power acoustic extinguisher, and then the original experiments and analyses of extinguishing effectiveness were carried out. For extinguishing, waveforms with specified parameters selected symmetrically around the frequency for which the extinguisher was designed were used. The aim of this article is to present and discuss selected measurement results concerning the possibility of flame extinguishing with the use of sinusoidal acoustic waves of low frequency (below $21 \mathrm{~Hz}$ ), as well as with the use of frequency sweeping techniques with set parameters. Such an extinguisher can be equipped with an intelligent module so that the extinguisher may be activated automatically (without human intervention) when flames are detected. The benefits of this combination as well as the importance of image processing for flame detection are also presented in this paper. This solution, with its good fire detection and fast response, may be applicable for extinguishing firebreaks in particular.
\end{abstract}

Keywords: acoustic extinguisher; acoustic wave fire suppression; acoustic wave propagation; fire detection; firefighting; fire retardation

\section{Introduction}

Symmetry plays a key role in signal processing, regardless of its nature. Signal processing, as an interdisciplinary field included in several scientific fields, deals with performing specific operations on signals and interpreting those signals. In the 21st century, innovative ways to extinguish flames are still being sought. Since fires threaten human and animal life and degrade the environment, crisis management scenarios also include these spontaneous uncontrolled phenomena. The growing interest in robotics and economic factors in crisis management have influenced the scope of ongoing work in this area [1-3]. Not only chemistry, but also informatics, electrotechnics, electronics, and even acoustics and ICT (information and communications technologies) are indicated as fields of scientific research in this area. Studies on the effectiveness of particular techniques and their application have been conducted for years [4-15]. A recent scientific novelty is the use of neural networks for flame detection and wireless links for communication with the extinguishing system (innovation), thanks to which - in the case of flame detection-the extinguishing system can switch on automatically. In this respect, numerous studies and works on image recognition as well as robotics and teletransmission are important [16-25]. Moreover, intensive scientific development has made it possible to use modulated waves as well as unmodulated waveforms to extinguish flames. In the second case, carrier waves are always emitted, regardless of the value of the modulating signal. Acoustic technique has been indicated as one of the innovative methods of extinguishing flames. The benefits of its use include, among others, lack of pollution, no need to replenish the extinguishing agent, 
and widely understood economic (cheaper than traditional methods of flame extinguishing) and environmental (acoustic waves are not a chemical product, and therefore do not pollute the environment) aspects.

According to the definition, signal processing refers to useful operations on or analysis of signals. This paper is devoted to the analysis of signals in terms of their extinguishing capabilities using large and very large acoustic powers. In this context, specific signals are generated and then the measurement data obtained are analyzed in terms of the sound pressure level at which the extinguishing effect is observed and the necessary power that should be applied to the sound source to achieve complete extinguishment of the flames. In this sense, the aim is to manipulate the parameters of the signals in such a way that the flames are fully extinguished. For this purpose, among others, waveforms using frequency sweeping techniques are used. The scientific efforts carried out in Kielce, supported by local and national entrepreneurs dealing with fire protection, have contributed to the development of a noninvasive acoustic fire extinguisher, taking into account the conceptual apparatus of physics and acoustics, which in the long-term perspective allowed for its construction [26]. Currently, the device is in the testing phase. During the research, using high and very high acoustic power, by trial and error, researchers noticed that this technique can be used to extinguish fires of different classes, which will be signaled later in the article. The target product for the industry can be, inter alia, a noninvasive acoustic extinguisher, using natural acoustic wave propagation mechanisms to extinguish flames both in closed and open spaces outside the building. Such a device may be equipped with artificial intelligence to enable flame detection using modern image processing techniques. As a result of the works carried out, a protection of the patent office has been obtained for four solutions allowing extinguishing flames with the use of acoustic waves [27-30].

It should be noted that there are also other solutions to extinguish flames with the use of acoustic waves generated in the sound source. They can be seen as state of the art and taken into account when describing the solutions in the field of the possibility of extinguishing flames with acoustic waves. In this context, in addition to the inventions from 5 April 1988 (no. 4,735,282) — "Device and circuit for the generation of vortex rings"; from 4 May 1999 (no. 5,899,685) — “Remote lighted wick extinguisher"; and from 12 August 2010 (no. 2010/0203460) — “Process of extinction, expansion and controlling of fire flames thru acoustic" should be indicated [31-35].

Currently, in Poland and worldwide, there are known research studies on the possibility of extinguishing flames with the use of acoustic waves [26,36-50]. It is worth noting that the research works in this field were the subject of the scientific efforts of the American agency DARPA, which develops new technologies for the country's defense [36]. Through the analysis of the literature on this subject, only a few videos and publications may be found, which confirms that this technique is still in the testing and development phase [37-50]. When analyzing the literature review, there are only a few papers that present the possibility of extinguishing flames with acoustic waves. Few of them are related to gaseous fuel. The process of extinguishing flames using low-frequency waves, depending on the power of the burner and the distance of the flame, is presented in the article [46]. In practice, the average flow effect does not depend on the frequency of excitation (it is noted that the value increases as the pressure increases) [46]. The flame is interrupted when a critical pressure level is reached. The interaction of acoustic waves results in its distortion, dispersion, and extinction. A thin but long flame is easier to extinguish than a wide (thick) flame [47]. From the firefighting perspective, it is crucial to determine the minimum sound pressure at which the effect of complete extinguishing of the flames is obtained and the power delivered to the sound source at which this phenomenon occurs. The process of flame stream rupture due to acoustic waves is described in [51]. Wrinkling of the flame is presented in [52,53], and its bifurcation in $[54,55]$. 
Both modulated and unmodulated waves can be used for firefighting purposes. The paper [26] presents the influence of acoustic pressure on the flame extinguishing process depending on the distance from the waveguide output for multiple frequencies. Empirically, the relationship between increasing distance from the waveguide output and decreasing sound pressure level was confirmed. It was shown that it is possible to extinguish flames with waves of a frequency different from that at which the minimum acoustic impedance was measured. However, the frequency mismatch adversely impacted the sound source, resulting in the vibration of its diaphragm. As the frequency increased, the need to raise the power delivered to the sound source was noted, at which the complete extinguishment of the flames was recorded. However, the question was whether acoustic waves of varying frequency can also be applied for flame extinguishing? An attempt to answer this question is one of the key objectives of this paper. It is worth emphasizing that, if it would be possible, such application of acoustic waves may be of great importance in extinguishing flames originating from different fuels, which would be difficult to extinguish with the classic means of fire protection. Moreover, there is a practical justification for using this technique in the future when classical fire protection means are unavailable or their quantity is limited at the place where flames occur.

There are few works that used low-frequency acoustic waves with low acoustic power delivered to the sound source, i.e., less than $30 \mathrm{~W}$, to extinguish flames. In terms of the analysis of the literature review, diffusion flame extinguishing (visualized with a streak apparatus) is included in the paper [44], taking into account the critical frequency and acoustic power. In practice, this paper presents results on the ability to extinguish a diffusion flame considering different signal parameters. It was shown that the flames could be extinguished by acoustic waves of different frequencies (35-155 Hz). However, the power applied to the sound source was low (less than $30 \mathrm{~W}$ ), resulting in a low sound pressure level. Since the extinguishing effect was observed for a few centimeters from the output of the waveguide, which was unsatisfactory, it was then recognized that there was a need to continue the research in the future using much higher powers [44,47]. During that research, it was observed that extinguishing depends on the frequency of the acoustic wave (the lower the frequency, the greater the extinguishing ability of the wave). Previous research indicates that the application of low-frequency waves (below $100 \mathrm{~Hz}$ ) has a beneficial effect on the combustion process [56-58], while the combustion may be discontinuous [59]. Moreover, in the article [56], it was stated that using low-frequency waves it is easier to extinguish flames. This is related to the fact that for waves with frequencies lower than $100 \mathrm{~Hz}$, a reduction in the burning rate is recorded [57], which depends on the type of fire (e.g., when extinguishing liquid flames, there is additionally evaporation). Acoustic waves with low frequencies cause more flame turbulence and thus show higher flame extinguishing efficiency. Similarly, the paper [58] showed that it is easiest to extinguish flames using the lowest possible frequency from the range analyzed. Furthermore, the paper [56] suggested that further decreasing the frequency may have a beneficial effect on extinguishing flames using acoustic waves. For these reasons as well as on the basis of our own analysis, the extinguisher was designed for a frequency of $17 \mathrm{~Hz}$, and its operating frequency range was chosen in a non-coincidental way.

In the experiments presented in this article, low-frequency waves (below $21 \mathrm{~Hz}$ ) were used for extinguishing. The choice of operating frequency $(f=15 \mathrm{~Hz}, \mathrm{f}=18 \mathrm{~Hz}, \mathrm{f}=21 \mathrm{~Hz})$ was dictated by the fact that a minimum value of acoustic impedance (11.4 $\Omega$ ) was obtained at $17.25 \mathrm{~Hz}$. The selected frequencies were in a symmetrical arrangement around the frequency for which the extinguisher was designed. It is worth noting that both the power curve and the sound pressure curve had local maxima that were close to the frequency for which the acoustic extinguisher was designed, i.e., $17 \mathrm{~Hz}$. Moreover, as previously mentioned, to fill the literature gap, this study applied much higher powers than those used thus far to extinguish the flames, which made it possible in practice to increase the range of use of acoustic technology for flame extinguishing. This reaffirms the fact that this technology is not fully discovered. In the existing literature, no research results allowing 
for extinguishing flames from considerable distances have been found, which is possible thanks to the use of large and very large powers, as well as frequency sweeping techniques. Therefore, there was a need to fill the literature gap in this area. A candle was used to clearly determine the extinguishing capacity of the wave. The article therefore fills a gap in the literature by showing the possibility of extinguishing flames whose fuel was wax using acoustic waves of low frequencies (below $21 \mathrm{~Hz}$ ). A scientific novelty is the extinguishing of flames at a considerable distance from the waveguide output, made possible by using a high-powered sound source. The use of frequency sweeping techniques to extinguish flames is also an original approach. During the research reported in this article, this has been proven to be possible. This may be of potential importance when extinguishing fires of different classes (extinguishing frequency changes).

It should be noted that acoustic flame extinguishing technology is currently at an early stage of development (its operating range is a few meters at most). In practice, acoustic extinguishers may serve as one of the means of fire protection. They can be installed permanently in areas particularly prone to fire (indoor environments), as well as constituting movable devices that are one of the components of the firefighting system that is installed in robots equipped with artificial intelligence (such applications, for illustrative purposes, will be signaled in Section 3.5). When intelligent sensors are used, the environmental changes and ambient conditions do not affect their functioning. Moreover, there is an economic factor behind the use of intelligent sensors because they are cheap. For the above reasons, these sensors are increasingly applied. It is possible to derive benefits from both technologies (acoustic extinguishing of flames detected with the use of an intelligent sensor) by combining these techniques, the results of which have been presented as part of the work conducted in Polish-Bulgarian cooperation [48-50].

The article consists of several sections. First, a brief introduction is provided. Then, the research methods used are discussed as well as the results including: sound pressure level characteristics as a function of power supplied to the extinguisher, sound pressure level characteristics as a function of distance from the extinguisher output, sound pressure level and power characteristics as a function of frequency, flame extinguishing with frequency sweeping techniques - analysis of a case, and for illustrative purposes-the use of an artificial intelligence platforms for flame detection. Discussion of results and conclusions are also included. The main aim of this article is to present the results of the research in the field of flame extinguishing with the use of acoustic waves (to supplement knowledge in this area). In addition, it is shown that signal processing using artificial intelligence is applicable in fire protection (currently many research centers around the world are conducting research on the use of artificial intelligence for flame detection). Such an intelligent module can cooperate with the acoustic fire extinguisher, which is a new approach in the field of fire protection and the use of image processing in acoustic technology. It is worth emphasizing that the primary objective of this paper is not the processing of video sequences (video signals), which is a subfield of digital signal processing, but the analysis of flame suppression capabilities using low-frequency acoustic waves and frequency sweeping techniques. Therefore, new algorithms for image processing, analysis, and recognition (discrimination) have been omitted from this article. Information on this topic can be found in the bibliography of the article [60-65]. A comparative summary is given in the article [66]. This paper presents the results of the acoustic wave research with data on actual flame and fire suppression (this is completed with data from actual fire tests). In this case, as previously indicated, low-frequency acoustic waves of three frequencies ( $\mathrm{f}=15 \mathrm{~Hz}, \mathrm{f}=18 \mathrm{~Hz}, \mathrm{f}=21 \mathrm{~Hz}$ ), as well as frequency sweeping techniques in the frequency range from $16 \mathrm{~Hz}$ to $18 \mathrm{~Hz}$, depending on the tuning time, which did not exceed $750 \mathrm{~ms}$, were applied. It should be noted that in this article, the flame suppression means such a controlled suppression of the flame that, under given parameters, results in its complete extinguishment. Therefore, suppressing flames allow to extinguish the fire in each of the cases analyzed. 


\section{Materials and Methods}

Symmetry has an important function in signal processing, as it can be exploited to minimize the complexity of problems that involve a variety of application areas of modern life. One possibility that has recently emerged is the use of unmodulated waves and frequency sweeping techniques to extinguish flames. For this purpose, the experimental method, the comparative method, and the individual case method (extinguishing flames using acoustic waves with given parameters) were used.

The experimental measuring station, in addition to the prototype of the acoustic extinguisher, consists of such components as: Rigol DG4102 generator with the possibility of generating modulated waveforms, Proel HPX2800 power amplifier, SVAN 979 sound meter, and electric quantity meters (current, voltage, and power). As previously indicated, the source of the flames was a candle placed in the axis of the waveguide, behind the output of the device. In this way it was possible to clearly observe the moment when the flame was extinguished depending on the parameters of the acoustic wave. In practice, the flame extinguishing was also tested with the use of a professional gas fuel mock-up. In these experiments with the gas mock-up, it could be observed that if the flames were not completely extinguished, the fuel was reignited after a while, and the mock-up burst into flames again. This factor led to the choice of a point fire source for these experiments, which was a burning candle with a flame height of about $2 \mathrm{~cm}$. Therefore, a candle with wax fuel was used instead of a diffuse fire source.

The research on the extinguishing capability of acoustic waves was divided into two groups (the influence of frequency on the minimum power delivered to the loudspeaker at which the extinguishing effect is observed and the influence of frequency on the minimum sound pressure causing the extinguishing effect are presented). The power applied to the loudspeaker was systematically increased until extinguishing of the flames was observed. Then the measurements were repeated, and the sound pressure level at which the flames were extinguished was measured. A prototype of the acoustic extinguisher with a visible output is shown in Figure 1. This is a closed end tube.

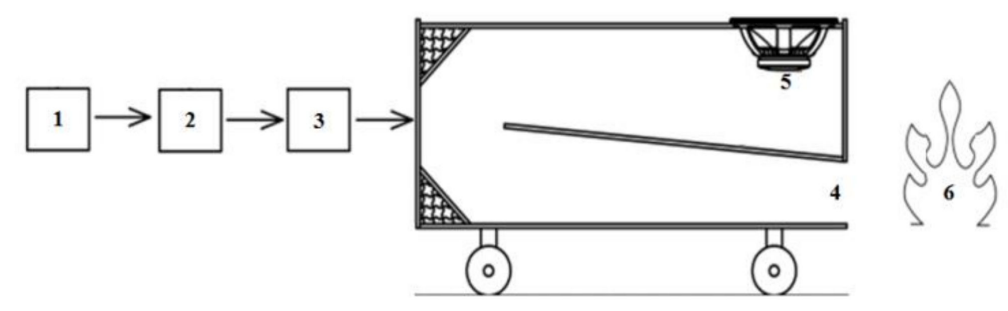

Figure 1. Components of acoustic fire extinguisher: (1) signal generator, (2) modulator, (3) amplifier, (4) output, (5) speaker, (6) flame source.

The principle of operation of the waveguide is to amplify the wave through the phenomenon of acoustic resonance, resulting from reflections of the wave propagating inside the waveguide. Detailed information on the design of this acoustic extinguisher can be found in [26]. All extinguishing tests were conducted for safety in the open space outside the building.

\section{Results}

In each subsection, the results of the measurements are presented. The experimental research was divided into two parts. The first part (Sections 3.1 and 3.2) contains information about the acoustic extinguisher, which influenced the selection of its performance during the actual extinguishing process (in this regard, curves including sound pressure level characteristics as a function of the power supplied to the extinguisher, and sound pressure level characteristics as a function of distance from the extinguisher output were presented). On this basis, one is able to know the properties of an acoustic extinguisher for the frequency for which it was designed, i.e., $17 \mathrm{~Hz}$. In practice, fire extinguishing is also 
possible with other frequencies, both lower and higher than the frequency for which the fire extinguisher was designed, but very good effectiveness was recorded for frequencies close to this frequency. Data on flame extinguishing capabilities are presented in the next two subsections (Sections 3.3 and 3.4), which contain information on the extinguishing model fire source (in this regard, data about sound pressure level and power characteristics as a function of frequency as well as flame extinguishing with frequency sweeping techniques were included). It is worth emphasizing that in these two subsections, the results of research presenting the possibility of extinguishing flames with the high-power acoustic extinguisher were analyzed (this is a scientific novelty, as in the literature, there are publications presenting only the use of small powers for extinguishing flames). For this purpose, the power and sound pressure level at which the flames were successfully extinguished were determined for the given frequencies. The last subsection (Section 3.5) shows the possibilities of the use of image processing (artificial intelligence) for flame detection. Such research, carried out in the framework of Polish-Bulgarian cooperation, represents a new approach in the field of fire protection.

\subsection{Sound Pressure Level Characteristics as a Function of Power Supplied to the Extinguisher}

In practice, the extinguishing effect depends on the selection of frequency. The use of low frequencies for flame extinguishing is desirable due to the need to supply less electrical power to the extinguisher, which in turn translates into a lower sound pressure measured at the place of the flame. Below are the results of sound pressure measurements in the waveguide axis, as a function of the power supplied to the extinguisher for the sinusoidal waveform at a distance of $2 \mathrm{~m}$ from the device output (Figure 2). Waves with an operating frequency of $17.25 \mathrm{~Hz}$ were used. It is worth noting that the minimum value of acoustic impedance $\left(Z_{\min }=11.4 \Omega\right)$ was obtained for this frequency. As previously mentioned, the extinguisher was designed to operate at $17 \mathrm{~Hz}$, and thus the measurements proved that this design intent was met. This means that the device had the best extinguishing capability at the indicated frequency, which was confirmed experimentally both by the identification of extinguishing parameters (including the impedance curve) and during flame extinguishing tests. The analysis of measurements of the extinguisher impedance curve, which was determined in the frequency range from $10 \mathrm{~Hz}$ to $90 \mathrm{~Hz}$, was applied for this purpose. In practice, for the frequency of $17.25 \mathrm{~Hz}$, the highest extinguishing range of the analyzed frequencies was obtained. This was due to the fact that for this frequency, the vibrations of the speaker's cone were the smallest, which allowed for the most effective use of the speaker's power capabilities during extinguishing. Figure 2 presents the sound pressure level as a function of power, at a distance of $2 \mathrm{~m}$ from the device output, for the sinusoidal wave of $17.25 \mathrm{~Hz}$.

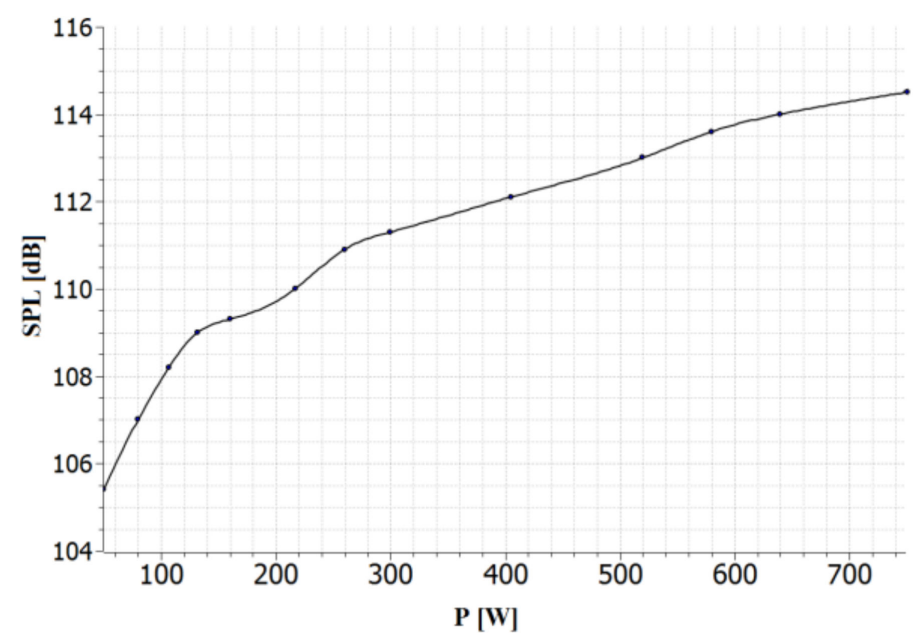

Figure 2. Sound pressure level measurement (SPL) as a function of the power supplied to the extinguisher $(\mathrm{P})$ at a distance of $2 \mathrm{~m}$ from the device output. 
As it can be expected, a gradual increase in the sound pressure level was observed with the increase in power. For the power of $50 \mathrm{~W}$, the sound pressure was equal to $105.4 \mathrm{~dB}$, for $80 \mathrm{~W}-107 \mathrm{~dB}$, for $107 \mathrm{~W}-108.2 \mathrm{~dB}$, for $132 \mathrm{~W}-109 \mathrm{~dB}$, for $160 \mathrm{~W}-109.3 \mathrm{~dB}$, for $217 \mathrm{~W}-110 \mathrm{~dB}$, for $260 \mathrm{~W}-110.9 \mathrm{~dB}$, for $300 \mathrm{~W}-111.3 \mathrm{~dB}$, for $405 \mathrm{~W}-112.1 \mathrm{~dB}$, for $520 \mathrm{~W}-113 \mathrm{~dB}$, for $580 \mathrm{~W}-113.6 \mathrm{~dB}, 640 \mathrm{~W}-114 \mathrm{~dB}$, and for $750 \mathrm{~W}-114.5 \mathrm{~dB}$. In general, the aim was to keep the sound pressure level as low as possible at the extinguishing point, but sufficient enough to extinguish the flames quickly and effectively. Therefore, it is possible to introduce into the literature of the subject matter the concept of the sound pressure reserve, which is the excess sound pressure added to the minimum sound pressure at which the flame extinguishing effect is observed. Such a reserve should be seen as a correction for unfavorable extinguishing conditions.

\subsection{Sound Pressure Level Characteristics as a Function of Distance from the Extinguisher Output}

An important issue is also to determine the possibility of extinguishing the flames depending on the distance of the flame front from the plane of the waveguide output. Thus, for sinusoidal waves with the operating frequency of $17.25 \mathrm{~Hz}$, experimental tests were carried out to illustrate the dependence of the sound pressure level as a function of distance from the device output (Figure 3). The measurements were carried out with a step of $0.1 \mathrm{~m}$, but below, due to the multiplicity of measurement data, they will be presented descriptively with a step of $0.5 \mathrm{~m}$. For $34.5 \mathrm{~W}$ and $0.1 \mathrm{~m}$ distance from the device output, the sound pressure level was equal to $124.2 \mathrm{~dB}$, for $0.5 \mathrm{~m}-116 \mathrm{~dB}$, for $1 \mathrm{~m}-109.9 \mathrm{~dB}$, for $1.5 \mathrm{~m}-106.3 \mathrm{~dB}$, for $2 \mathrm{~m}-103.7 \mathrm{~dB}$, for $2.5 \mathrm{~m}-101.9 \mathrm{~dB}$, for $3 \mathrm{~m}-100.5 \mathrm{~dB}$, for $3.5 \mathrm{~m}-99.5 \mathrm{~dB}$, for $4 \mathrm{~m}-98.8 \mathrm{~dB}$, for $4.5 \mathrm{~m}-98.2 \mathrm{~dB}$ and for $5 \mathrm{~m}-97.8 \mathrm{~dB}$.

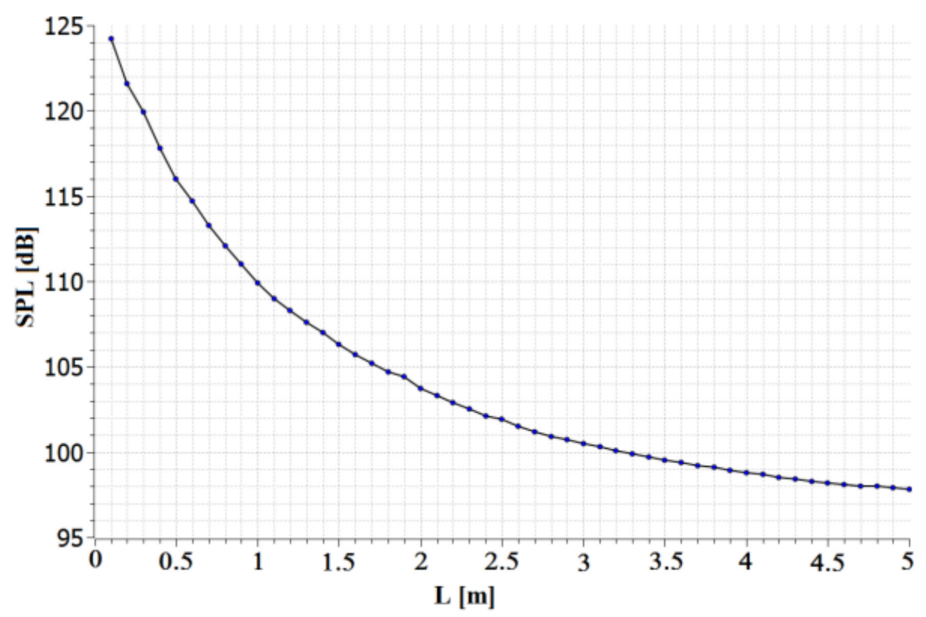

Figure 3. Sound pressure level measurement (SPL) as a function of the distance (L) from the extinguisher output to the waveguide axis.

On the basis of the results obtained, one can see a noticeable tendency function of the sound pressure dependence as a function of the distance from the device output (this is a downward trend). Since an inversely proportional drop in sound pressure level is recorded as a function of the distance from the device output, more power of the sound source is required to extinguish the flames at a considerable distance from the output. It should be understood that it is easier to extinguish the flames located closer to the device output than at a significant distance from it, because it involves the need to increase the electrical power supplied to the sound source, which in turn translates into the level of sound pressure necessary to disperse the flames, break them into pieces, and then extinguish them. The mechanism is complex and depends also on the flow effect. An additional problem is the omnidirectional shape of the acoustic beam. While the main acoustic flux occurs in the waveguide axis, which was confirmed by experimental research on the prototype of the device [26], the losses resulting from the omnidirectional emission contributed to the reduction of the distance for which effective flame extinguishing was recorded. Therefore, 
when designing an extinguishing system, it is worth taking into account the multipoint arrangement of sound sources so that the acoustic flux, as precisely as possible, is directed to the source of the flames, with a safe sound pressure level. This is also influenced by the natural physical mechanisms accompanying the propagation of acoustic waves.

\subsection{Sound Pressure Level and Power Characteristics as a Function of Frequency}

As previously mentioned, the extinguishing capabilities of the device will be shown in this section. The data presented in this article will refer to both the power to be applied to the sound source, which was a woofer, and the sound pressure at which the flame extinguishing effect was observed. In practice, low-frequency acoustic waves interact with the flames, causing them to deflect, break into parts, and disperse, while not always observing the effect of complete extinguishing of the flames, which is crucial for firefighting. For practical reasons, it is necessary to manipulate the flame in such a way that it is completely extinguished. Therefore, in the following part of the article, the results of experimental data for high acoustic power (scientific novelty), for several measurement points (the step was equal to $3 \mathrm{~Hz}$ ), will be analyzed, illustrating the necessary power to be applied to the loudspeaker as well as the acoustic pressure at which the extinguishing effect was observed.

It should be emphasized that in this paper that the extinguishing effect is understood as the phenomenon of complete extinguishing of the flames using low-frequency acoustic waves, which was observed with an appropriate choice of parameters. Therefore, the extinguishing of the flames will mean their complete extinguishment and only these results, illustrating the minimum power that had to be delivered to the sound source to extinguish the flames as well as the sound pressure level at which the tests were successful, are presented. As a part of the research, experiments showing the sound pressure level for a given distance from the device output, for sinusoidal waves of three frequencies close to the operating frequency $(\mathrm{f}=15 \mathrm{~Hz}, \mathrm{f}=18 \mathrm{~Hz}, \mathrm{f}=21 \mathrm{~Hz})$, were conducted. Figure 4a shows a diagram of the sound pressure as a function of frequency, at a distance of $0.5 \mathrm{~m}$ from the device output. On this basis, it is possible to analyze the influence of the frequency of the acoustic wave on the minimum sound pressure level at which the flames may be extinguished. The intensity of the background noise accompanying the measurements was equal to $64.7 \mathrm{~dB}$. The measurement time of each data sample was equal to $5 \mathrm{~s}$. In turn, Figure $4 \mathrm{~b}$ shows a diagram of the influence of the acoustic wave frequency on the minimum electrical power supplied to the sound source to extinguish the flames.

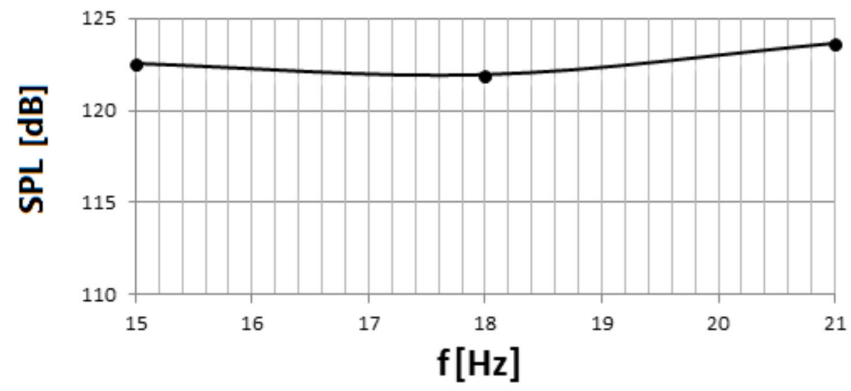

(a)

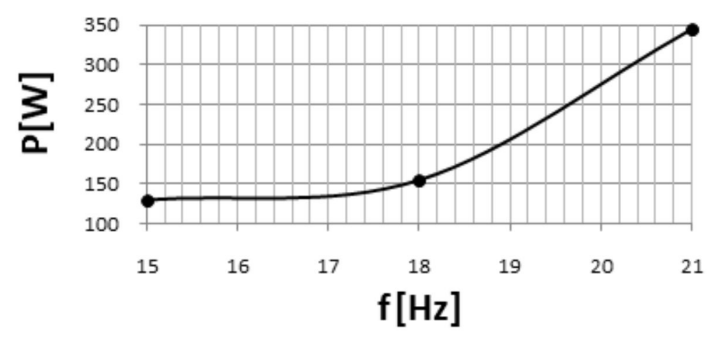

(b)

Figure 4. (a) Sound pressure level measurement (SPL) as a function of the acoustic wave frequency (f) in the waveguide axis. (b) Electrical power measurements $(\mathrm{P})$ as a function of the acoustic wave frequency (f).

Figure $4 \mathrm{a}, \mathrm{b}$ is based on the actual measurement data from the same extinguishing test. Both the power delivered from the amplifier to the loudspeaker and the sound pressure at which the effect of complete extinguishing of the flames was obtained were measured. Results presented in Figure 4a suggest that slight differences in sound pressure level can be observed (the maximum difference for these measurements was equal to $1.7 \mathrm{~dB}$ ). In 
the range of frequencies analyzed, a gradual increase in sound pressure was noted with an increase in the electrical power supplied to the loudspeaker. This was due to the fact that the level of sound pressure was logarithmically dependent on the power that was delivered to the sound source (see the experimental curve in Figure 2). However, it is important to note that a linear increase in sound pressure was only observed over a certain range, as the sound field can also have a nonlinear character [59]. The recorded sound pressure level, at which the extinguishing effect was obtained, ranged from $122.5 \mathrm{~dB}$ to 123.6 dB. To extinguish the flames, it was important to ensure a minimum sound pressure level at which the flames would be effectively extinguished. It is recommended to take a correction for the reserve sound pressure at the extinguishing system design stage. On the basis of the results presented in Figure $4 b$, it is clear that as the frequency increased, the power to be supplied to the sound source to extinguish the flame increased, which clearly confirmed that not only the distance of the flame front from the extinguisher's output plane affected the extinguishing process, but also the frequency. For waves with a frequency of $15 \mathrm{~Hz}$, the minimum extinguishing power was equal to $130 \mathrm{~W}$, for $18 \mathrm{~Hz}-155 \mathrm{~W}$, and for $21 \mathrm{~Hz}-345 \mathrm{~W}$. Hence, the electrical power, depending on the tested frequency at which the extinguishing effect was observed, ranged from 130 to $345 \mathrm{~W}$.

The results suggest that it is possible to extinguish the flames for a wide spectrum of frequencies (lower and higher than the operating frequency), but it should be noted that the distance between the device output and the flame source is also significant (Figure 3), which is connected with the need to provide the sound source with the adequate electrical power necessary to extinguish the flames. In practice, the sound pressure level and power characteristics have local maxima depending on the frequency of extinguisher work. Acoustic waves with a lower frequency than the operating frequency $(17.25 \mathrm{~Hz})$ are favorable for extinguishing the flames as they cause more turbulence. On the other hand, if the waveguide does not match the capabilities of the speaker, their use is associated with significant vibration of the speaker cone (the amplitude of the vibrations increases substantially), which is an undesirable effect. This is related to the reduction of the range of the acoustic extinguisher due to the constructional limitations of the loudspeaker. In turn, the use of acoustic waves at a higher frequency than the operating frequency results in an increase in the power required to extinguish the flames.

\subsection{Flame Extinguishing with Frequency Sweeping Techniques-Analysis of a Case}

The research also analyzed the possibility of extinguishing the flames with the use of the frequency sweep technique. Sinusoidal acoustic waves were used for this purpose. In the 'Sweep' mode, the signal frequency changes from the start value (start frequency) to the end value (stop frequency) at the set time. For demonstration purposes, the flame front was placed at a distance of $L=1.5 \mathrm{~m}$ from the waveguide output plane. The intensity of the background noise accompanying the measurements was equal to $64.7 \mathrm{~dB}$. The purpose of these measurements was to determine the necessary electrical power to be supplied to the sound source to extinguish the flames depending on the set parameters, i.e., the frequency range and the tuning time, which did not exceed $750 \mathrm{~ms}$. The set parameters are shown in Table 1.

Table 1. Parameters used to extinguish flames using frequency sweeping technique ${ }^{1}$.

\begin{tabular}{cc}
\hline Frequency Range $\mathbf{( H z )}$ & Tuning Time $(\mathbf{m s})$ \\
\hline $16-18$ & 500 \\
$17-18$ & 125 \\
$17-18$ & 500 \\
$17-18$ & 750 \\
\hline
\end{tabular}

${ }^{1}$ As a reminder, the extinguisher was designed for a frequency of $17 \mathrm{~Hz}$, and thus the choice of the frequency range was not accidental. 
Flames can be extinguished by means of acoustic waves, especially with low frequency, and expectations connected with the attempts to extinguish the flames with the use of frequency sweeping techniques were met. As in the previous section, the suppression efficiency was determined by whether the flames were completely extinguished under the particular conditions, with the given parameters. If so, the power that had to be delivered to the loudspeaker to observe the effect of complete extinguishment of the flames was measured. This allowed us to assume the hypothesis that acoustic waves of sweeping (changing) frequency may also be effectively applied to extinguish the flames (scientific novelty). An important factor is the tuning time. For waves with frequencies ranging from 17 to $18 \mathrm{~Hz}$, depending on the tuning time, the minimum power at which the extinguishing effect was observed was equal to $460 \mathrm{~W}$. Tests with higher power $(700-750 \mathrm{~W})$ were also successful. It was noticed that the adjustment of the tuning time, in the range of $125-750 \mathrm{~ms}$, influenced the need to change the electrical power at which the extinguishing effect was recorded. In the case of changing the frequency range to lower (from 16 to $18 \mathrm{~Hz}$ ), the extinguishing attempts were also successful $(\mathrm{P}=700 \mathrm{~W})$. In some cases (when the tuning time was equal to $750 \mathrm{~ms}$ ), it was not possible to extinguish the flames for the given parameters, because it would be necessary to supply more power to the sound source. As a consequence, the insufficient level of turbulence of the sound pressure was noticed, which led to inadequate expansion and breaking of flames, and thus the lack of extinguishing effect. Because the extinguisher was designed for $17 \mathrm{~Hz}$, the use of lower frequency acoustic waves was connected with the constructional limitations. The problem was the significant deflection of the loudspeaker cone, which operates in unfavorable conditions, with no acoustic load on the waveguide.

\subsection{The use of an Artificial Intelligence Platform for Flame Detection}

Image processing has many applications, which may be exemplified by vision systems equipped with artificial intelligence, which can support human work in firefighting operations. Both visible and infrared band imaging can be applied for this purpose. In practice, the acoustic fire extinguisher can be equipped with an intelligent sensor so that there is no need to use traditional smoke and temperature sensors [48-50]. This application of artificial intelligence is particularly suitable in places where the use of classical sensors is hampered. Therefore, the most common destination of these sensors is the flame detection in the open space outside the buildings. The advantage is the high speed of data processing (less than $10 \mathrm{~ms}$ ), and thus the time delay practically does not exist (a human does not participate in the data processing chain). A recent innovation is the use of artificial intelligence to detect flames. Equipping an acoustic fire extinguisher with an intelligent module may allow the flames to be extinguished automatically if detected without human intervention. From a practical point of view, there is then almost no time delay between the detection of the flame and the start of the extinguishing action. This technique can be used primarily to quickly extinguish firebreaks.

Research into flame detection using artificial intelligence is relevant in this area. Visual salience has an important role in deepening awareness of the environment being analyzed. For illustrative purposes, example images used in the development of the acoustic fire extinguisher equipped with a deep neural network module are provided in Figure 5 [49].

An image that has a single flame is easier to process than an image that will contain multiple flames. There are many categories of fire detection methods. Some of them use color rules and some use machine learning. Detailed considerations on this matter are included in [60-65]. To be able to properly select the color space and fire pixel detection rules, the use of multiple images is recommended [65]. Since the models in RGB color space are sensitive to luminance changes, among others, chromatic models in $\mathrm{YCbCr}$ and $\mathrm{HSV}$ spaces are applied. Machine learning based on logistic regression may achieve very good robustness to smoke and color changes [65]. What is new in recent years is the research in terms of the possibility of using vision systems equipped with artificial intelligence that can support human work in firefighting operations [60-65]. This is essential, because during a 
fire, help should be brought to where it is most necessary. Artificial vision systems may be a part of wheeled mobile robots or special purpose robots as shown in [61]. The concept of human-like visual attention-based artificial vision (HVAAV) achieves visual attention similar to humans by using machine learning [61]. Hybridization allows parameters to be adjusted to the manner in which humans perceive reality. The Wifibot-M from NEXTER Robotics, among others, can be used for this purpose. In this case, the control may be implemented using a joystick or a virtual simulation [61]. In turn, papers [48-50] describe examples of a hardware fire detection module in terms of the possibility of the use of deep neural networks for flame detection in the acoustic extinguisher. As previously indicated, the main aim of this paper was to analyze the possibility of flame suppression using low frequency acoustic waves and frequency sweeping techniques. For this reason, the paper omitted new algorithms for image processing, analysis, and recognition (discrimination). Information on this topic can be found in the bibliography of the article [60-65]. A comparative summary is provided in [66]. Nevertheless, the essence of vision processing in combination with the acoustic extinguisher was signaled, which is the subject of other articles cited in the bibliography of this paper [48-50]. In this context, for image processing, the Open Source Computer Vision Library (OpenCV) was applied. Such a module can be integrated into the acoustic fire extinguisher (its detection efficiency is over $70 \%$ ). This is essential because the acoustic system does not need to be manually switched into active mode by a human. A deep neural network detects the flames, and if there are identified, the acoustic extinguisher may be activated automatically. Ongoing research is looking at combining the two techniques, making it possible to detect flames using an intelligent sensor and then extinguish them with eco-friendly acoustic technology using low-frequency acoustic waves and frequency sweeping techniques.

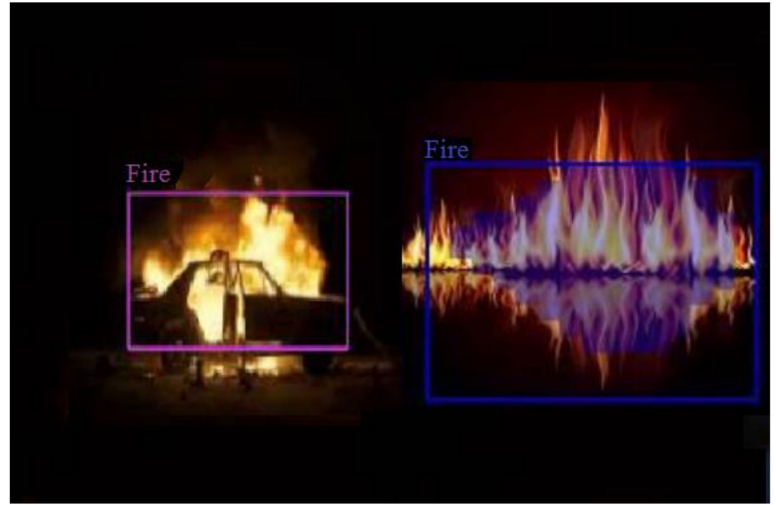

(a)

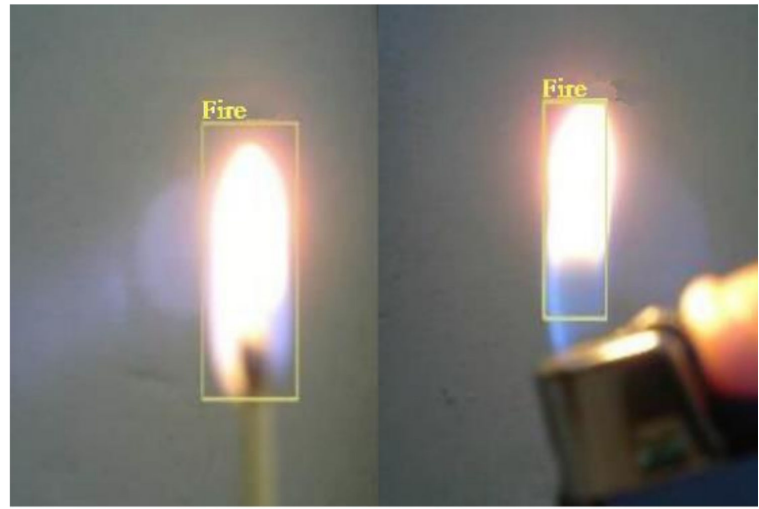

(b)

Figure 5. (a) Example of images used to test deep neural networks. (b) Example of actual camera images used to test deep neural networks.

\section{Discussion}

This paper presents the possibility of extinguishing flames with the use of acoustic waves for the specified parameters. Flame extinguishing is possible at a number of frequencies, both lower and higher than the frequency at which the extinguisher is designed, and that when lower frequencies are used, it is observed that the amplitude of the vibrations increases (the waveguide is then not compatible with the loudspeaker), while at higher frequencies, an increase in the energy of the subacoustic power is noted. This is due to the fact that, from a physical point of view, a departure from the resonant frequency results in a detuning from the resonant optimum, which translates into an increase in the required power to extinguish the flames. The limiting frequency above which the flame extinguishment was not observed was equal to $22 \mathrm{~Hz}$. Therefore, the last frequency for which the measured results were presented was equal to $21 \mathrm{~Hz}$. On the other hand, 
reducing the frequency is possible, but then the waveguide will be longer, which is a significant inconvenience, especially when building portable acoustic extinguishers.

As indicated earlier, the acoustic method seems to be promising for extinguishing flames, especially in areas where access to traditional extinguishing agents is limited or when it is difficult to extinguish flames due to the composition of the substance. In this regard, works in terms of image processing are also significant. This allows artificial intelligence to support the work of humans and firefighters. This technique is relatively new, and there is little research in this area. All experimental research carried out confirmed the effectiveness of extinguishing flames with low-frequency acoustic waves. The advantages of the technology include, among others, (A) lower cost of exploitation and extinguishing flames than in the case of traditional methods using consumable extinguishing agents (powders, foams, gases); (B) noninvasive character of operation (acoustic waves are not a chemical product) in contrast to the typical extinguishing agents, e.g., halon is particularly dangerous due to its adverse effects on human health and therefore, in accordance with EU guidelines, halon extinguishers are effectively withdrawn from production; (C) no need to undergo cyclic pressure tests, which are mandatory for traditional fire extinguishers (once in 10 years); (D) unlimited operating time in contrast to typical fire extinguishers (because the device uses properly generated modulated or unmodulated waves, only battery or mains supply sources are required); (E) the fact that the extinguisher may be permanently installed, e.g., in the building or vehicle construction stage (e.g., in server rooms, industrial buildings, tanks for liquids and flammable gases) in places that are difficult to access; (F) the acoustic wave extinguishing system can be connected to the acoustic warning system containing smoke and temperature detectors (so that human presence during extinguishing does not have to be required at all); and furthermore $(G)$ the acoustic wave system may be linked to low-cost autonomous intelligent sensors or actuators, and wireless sensor networks. In this respect, research is being carried out at the Technical University of Bulgaria, which resulted, among others, in joint scientific publications on the use of the intelligent module in the acoustic extinguisher. In general, neural networks are applied for reconnaissance purposes whether a fire has occurred, if so-the acoustic system can be switched on automatically (remotely) [48-50].

\section{Conclusions}

Symmetry has an important role in signal processing as it may be applied to minimize the complexity of a problem that affects various application areas of modern life. In practice, signal processing has many applications. Advances in computer systems are opening up many new opportunities that allow for a synergistic relationship between theoretical approaches and the construction of new systems for different purposes. They can also be found in the area of fire protection. In the 21st century, noninvasive and environmentally safe ways of extinguishing flames are sought after in many academic and scientific centers around the world. As shown in the paper, systems using artificial intelligence and acoustic technology can work together. The benefit of image analysis and recognition is then that practically there is no time delay between the flame detection and the start of the extinguishing action (the processing time is usually less than $10 \mathrm{~ms}$ ). Image processing performed in both the visible and infrared bands is then a key issue to flame detection.

In practice, low-frequency acoustic waves are difficult to suppress. This disadvantage becomes their greatest advantage, because the benefit of using acoustic waves is that they pass through solids, liquids, and gases as well. They can be used to control both the extinguishing and burning of substances. Typically, fire extinguishers filled with chemicals selected according to the type of fire are used to extinguish the flames. With acoustic technology, the extinguisher is the same-only the frequency and parameters of the wave are controlled, which is a definite advantage of this technology. A certain disadvantage is the size of the acoustic extinguisher, but this technology can be permanently installed in production halls. In this article, flames originating from a candle were extinguished (the fuel was wax). However, acoustic waves may be applied to extinguish Class B and C fires, 
i.e., when liquids or gases are burning. The results can be used in extinguishing systems, especially in places where the amount of traditional (chemical) extinguishing agents is limited (e.g., aircrafts, ships, and train decks, underground mine shafts), as well as for extinguishing flames that, due to their properties, cannot be extinguished by commonly known methods. This technique seems to be quite useful for putting out hydrocarbon pool fire. When using this technique for putting out hydrocarbon pool fires, it would be necessary to determine whether there is a limit at which (if the fuel is too hot or the pool fire is too large) the sound wave will not be able to extinguish the flames.

To sum up, this article presents a novel way in fire extinguishing. The paper investigated the capabilities of using acoustic waves to extinguish flames. Furthermore, frequency sweeping techniques were also applied. The article shows that it is possible to extinguish flames using acoustic waves even at a distance of $1.5 \mathrm{~m}$. It must be emphasized that this is an early prototype and works only on small fires. Nevertheless, with good fire detection and fast response, this solution may be applicable. To make this technology useful in the future, it is necessary to define the limits of its range of operation with the use of multipoint systems as well as to carry out tests in closed space and to refer to the safety of the people' usage of the technology, with particular emphasis on the sound pressure levels. It should be emphasized that for this technology to be fully exploited, a great deal of research is still needed aimed, inter alia, at analyzing the influence of acoustic pressure on human health (this is particularly important in the case of excessive acoustic pressure generation), as well as on building structures and room furnishings in terms of material strength analyses (walls, windows, etc.). Therefore, while acoustic technology has many of the advantages mentioned in the article and is environmentally friendly (acoustic waves are not a chemical creation), the uncontrolled use of acoustic waves with very high power delivered to the sound source may be a destructive force. In the future, there are plans to continue research into the use of low-frequency acoustic waves to extinguish flames from other fuels (including gaseous fuels) at high and very high power. Moreover, there is a need to continue this research to know and further detail the possibility of extinguishing the flames by means of acoustic waves for selected cases using acoustic systems equipped with artificial intelligence.

\section{Patents}

Urządzenie do gaszenia płomieni falami akustycznymi, by Wilk-Jakubowski, J. (30 November 2018). Patent PL, 233025, no application: P.427999.

Urządzenie do gaszenia płomieni falami akustycznymi, by Wilk-Jakubowski, J.

(30 November 2018). Patent PL, 233026, no application: P.428002.

Urządzenie do gaszenia płomieni falami akustycznymi, by Wilk-Jakubowski, J.

(13 Feburary 2018). Utility model PL, 070441, no application: W.127019.

Urządzenie do gaszenia płomieni falami akustycznymi, by Wilk-Jakubowski, J. (18 January 2019). Patent PL, 234266, no application: P.428615.

Funding: This research was funded by the Ministry of Science and Higher Education, grant InIn+ (no. 3/2017), grant letter of 24 May 2017.

Institutional Review Board Statement: Not applicable.

Informed Consent Statement: Not applicable.

Data Availability Statement: Not applicable.

Acknowledgments: The author would like to thank the company 'Ekohigiena Aparatura Ryszard Putyra Sp.J.', 19 Strzelecka St., 55-300 Środa Śląska, Poland and 'Przedsiębiorstwo HandlowoTechniczne SUPON Sp. z o.o.', 105 Sandomierska St., 25-324 Kielce, Poland for their support in the realization of the research.

Conflicts of Interest: The author declares no conflict of interest. 


\section{References}

1. Wilk-Jakubowski, G.; Harabin, R.; Ivanov, S. Robotics in crisis management: A review of the literature. Technol. Soc. 2021. under review.

2. Merrad, W.; Habib, L.; Héloir, A.; Kolski, C.; Krueger, A. Tangible tabletops and dual reality for crisis management: Case study with mobile robots and dynamic tangible objects. Procedia Comput. Sci. 2019, 151, 369-376. [CrossRef]

3. Wilk-Jakubowski, G. Normative Dimension of Crisis Management System in the Third Republic of Poland in an International Context. Organizational and Economic Aspects; Wydawnictwo Społecznej Akademii Nauk: Łódź/Warszawa, Poland, 2019.

4. Atay, H.Y.; Çelik, E. Multifunctional polymer composites: Antibacterial, flame retardant, radar absorbing and self-healing. J. Compos. Mater. 2014, 49, 2469-2482. [CrossRef]

5. Atay, H.Y.; Çelik, E. Use of Turkish Huntite/Hydromagnesite Mineral in Plastic Materials as a Flame Retardant. Polym. Compos. 2010, 31, 1692-1700. [CrossRef]

6. Atay, H.Y.; Çelik, E. Mechanical Properties of Flame-Retardant Huntite and Hydromagnesite-Reinforced Polymer Composites. Polym. Plast. Technol. Eng. 2013, 52, 182-188. [CrossRef]

7. Radwan, K.; Rakowska, J. Analiza skuteczności zastosowania wodnych roztworów mieszanin koncentratów pianotwórczych do gaszenia pożarów cieczy palnych. Przemyst Chem. 2011, 90, 2118-2121.

8. Loboichenko, V.; Strelets, V.; Gurbanova, M.; Morozov, A.; Kovalov, P.; Shevchenko, R.; Kovalova, T.; Ponomarenko, R. Review of the Environmental Characteristics of Fire Extinguishing Substances of Different Composition used for Fires Extinguishing of Various Classes. J. Eng. Appl. Sci. 2019, 14, 5925-5941. [CrossRef]

9. Dadashov, I.; Loboichenko, V.; Kireev, A. Analysis of the ecological characteristics of environment friendly fire fighting chemicals used in extinguishing oil products. Pollut. Res. 2018, 37, 63-77.

10. Dadashov, I.; Loboichenko, V.; Kireev, A. Comparative assessment of environmental damage when using gel forming systems of different composition in combustible liquids extinguishing. Trans. Kremenchuk Mykhailo Ostrohradskyi Nat. Univ. 2018, 1, 123-129. [CrossRef]

11. Tofiło, P.; Węgrzyński, W.; Porowski, R. Hand calculations, zone models and CFD—areas of disagreement and limits of application in practical fire protection engineering. In Proceedings of the XI Conference on Performance-Based Codes and Fire Safety Design Methods, Warsaw, Poland, 23-25 May 2016.

12. Porowski, R.; Lesiak, P.; Teodorczyk, A. Analiza zjawiska boilover podczas pożarów cieczy naftopochodnych magazynowanych w zbiornikach. Przemyst Chem. 2013, 92, 518-521.

13. Rudy, W.; Dabkowski, A.; Porowski, R.; Teodorczyk, A. Experimental and numerical study of spontaneous ignition of hydrogenmethane jets in air. In Proceedings of the XXIV International Colloquium on the Dynamics of Explosions and Reactive Systems, Taipei, Taiwan, 28 July-2 August 2013.

14. Jensen, G. Manual Fire Extinguishing Equipment for Protection of Heritage; COWI AS: Oslo, Norway, 2006.

15. Wnęk, W.; Kubica, P.; Basiak, M. Standardy projektowania urządzeń gaśniczych tryskaczowych-Porównanie głównych parametrów. Bezp. Tech. Pożar. 2012, 27, 83-96.

16. Foley, D.; O’Reilly, R. An Evaluation of Convolutional Neural Network Models for Object Detection in Images on Low-End Devices. In Proceedings of the 26th AIAI Irish Conference on Artificial Intelligence and Cognitive Science, Dublin, Ireland, 6-7 December 2018.

17. Kurup, R. Vision-Based Fire Flame Detection System Using Optical flow Features and Artificial Neural Network. Int. J. Sci. Res. 2014, 3, 2161-2168.

18. Janků, P.; Komínková Oplatková, Z.; Dulík, T. Fire detection in video stream by using simple artificial neural network. Mendel 2018, 24, 55-60. [CrossRef]

19. Szegedy, C.; Toshev, A.; Erhan, D. Deep Neural Networks for Object Detection. Adv. Neural Inf. Process. Syst. 2013, 26, 1-9.

20. Šerić, L.; Stipanicev, D.; Krstinić, D. ML/AI in Intelligent Forest Fire Observer Network. In Proceedings of the 3rd EAI International Conference on Management of Manufacturing Systems, Dubrovnik, Croatia, 6-8 November 2018. [CrossRef]

21. Mihelj, M.; Novak, D.; Beguš, S. Virtual Reality Technology and Applications; Part of the Intelligent Systems, Control and Automation (Science and Engineering Book Series); Springer: Dordrecht, The Netherlands, 2013. [CrossRef]

22. Wilk-Jakubowski, G. Wpływ technologii informatyczno-komunikacyjnych na bezpieczeństwo współczesnych społeczeństw. In Proceedings of the III Ogólnopolska Konferencja Naukowa Rola Informatyki w Naukach Ekonomicznych i Społecznych. Innowacje i Implikacje Interdyscyplinarne, Kielce, Poland, 15 September 2011.

23. Laganiere, R. Opencv 3 Computer Vision Application Programming Cookbook, 3rd ed.; Packt: Birmingham, UK, 2017.

24. Object Detection for Dummies Part 3: R-CNN Family. Available online: https://lilianweng.github.io/lil-log/2017/12/31/objectrecognition-for-dummies-part-3.html\#roi-pooling (accessed on 31 December 2017).

25. Simple understanding of Mask RCNN. Available online: https://medium.com/@alittlepain833/simple-understanding-of-maskrcnn-134b5b330e95 (accessed on 22 April 2018).

26. Stawczyk, P.; Wilk-Jakubowski, J. Non-invasive attempts to extinguish flames with the use of high-power acoustic extinguisher. Open Engineering 2021, 11, 349-355. [CrossRef]

27. Wilk-Jakubowski, J. Urządzenie do Gaszenia Płomieni Falami Akustycznymi. Patent PL 233025 No. Application: P.427999, 30 November 2018.

28. Wilk-Jakubowski, J. Urządzenie do Gaszenia Płomieni Falami Akustycznymi. Patent PL 233026 No. Application: P.428002, 30 November 2018. 
29. Wilk-Jakubowski, J. Urządzenie do Gaszenia Płomieni Falami Akustycznymi. Utility Model PL 070441 No. Application: W.127019, 13 February 2018.

30. Wilk-Jakubowski, J. Urządzenie do Gaszenia Płomieni Falami Akustycznymi. Patent PL 234266 No. Application: P.428615, 18 January 2019.

31. Davis, C.B. Fire Extinguishing Appliance and Appended Supplementary Appliances. U.S. Patent 4872511 No. Application 07/040393, 13 April 1987.

32. Wilczkowski, S.; Szecówka, L.; Radomiak, H.; Moszoro, K. Urządzenie do Gaszenia Płomieni Falami Akustycznymi. Patent PL 177478 No. Application: P.311910, 18 December 1995.

33. Wilczkowski, S.; Szecówka, L.; Radomiak, H.; Moszoro, K. Sposób Gaszenia Płomieni Falami Akustycznymi. Patent PL 177792 No. Application: P.311909, 18 December 1995.

34. Tran, V.; Robertson, S. Methods and Systems for Disrupting Phenomena with Waves. U.S. Patent 10569115 No. Application: 15/529,262, 24 November 2015.

35. Baokun, H.; Chengwen, Y.; Wenjie, C.; Wei, S. Low-Frequency Sound Wave Fire Extinguisher. Utility model CN, 204932657 No. Application: 201520680110, 6 September 2015.

36. DARPA Sound Based Fire Extinguisher. Available online: https://www.extremetech.com/extreme/132859-darpa-creates-soundbased-fire-extinguisher (accessed on 16 July 2012).

37. Myth Busters. Voice Flame Extinguisher, Episode 76. Available online: https://mythresults.com/episode76 (accessed on 11 April 2007).

38. Robertson, S.; Tran, V. Wave Extinguisher. Available online: https://ece.gmu.edu/ \{\}ppach/ECE_Awards/Posters/S-15-I.pdf (accessed on 11 May 2020).

39. Sai, R.T.; Sharma, G. Sonic Fire Extinguisher. Pramana Res. J. 2017, 8, 337-346.

40. Kim, M.-S.; Bae, M.-J. A study on a Fire Extinguisher with Sound Focus. Int. Inf. Inst. 2017, 20, 4055-4062.

41. Yi, E.-Y.; Bae, M.-J. A study on the directionality of sound fire extinguisher in electric fire. Converg. Res. Lett. Multimed. Serv. Converg. Art Humanit. Sociol. 2017, 3, 1449-1452.

42. Friedman, A.N.; Hughes, J.; Danis, P.I.; Fiola, G.J.; Barnes, C.A.; Stoliarov, S.I. Acoustically Enhanced Water Mist Suppression of Heptane Fueled Flames. Fire Technol. 2018, 54, 1829-1840. [CrossRef]

43. Kim, B.-Y.; Bae, M.-J.; Bae, S.-G. A study on suitability of sound fire extinguisher in duct environment. Int. J. Appl. Eng. Res. 2017, 12, 15796-15800.

44. Radomiak, H.; Mazur, M.; Zajemska, M.; Musiał, D. Gaszenie płomienia dyfuzyjnego przy pomocy fal akustycznych. Bezp. Tech Pożar. 2015, 40, 29-38. [CrossRef]

45. Niegodajew, P.; Gruszka, K.; Gnatowska, R.; Šofer, M. Application of acoustic oscillations in flame extinction in a presence of obstacle. In Proceedings of the XXIII Fluid Mechanics Conference (KKMP 2018), Zawiercie, Poland, 9-12 September 2018. [CrossRef]

46. Niegodajew, P.; Łukasiak, K.; Radomiak, H.; Musiał, D.; Zajemska, M.; Poskart, A.; Gruszka, K. Application of acoustic oscillations in quenching of gas burner flame. Combust. Flame 2018, 194, 245-249. [CrossRef]

47. Węsierski, T.; Wilczkowski, S.; Radomiak, H. Wygaszanie procesu spalania przy pomocy fal akustycznych. Bezp. Tech. Pożar. 2013, $30,59-64$.

48. Wilk-Jakubowski, J.; Stawczyk, P.; Ivanov, S.; Stankov, S. High-power acoustic fire extinguisher with artificial intelligence platform. Int. J. Comput. Vis. Robot. 2021. accepted for publication on 6 April 2021.

49. Wilk-Jakubowski, J.; Stawczyk, P.; Ivanov, S.; Stankov, S. The using of Deep Neural Networks and natural mechanisms of acoustic waves propagation for extinguishing flames. Int. J. Comput. Vis. Robot. 2021, in press. [CrossRef]

50. Ivanov, S.; Stankov, S.; Wilk-Jakubowski, J.; Stawczyk, P. The using of Deep Neural Networks and acoustic waves modulated by triangular waveform for extinguishing fires. New Approaches for Multidimensional Signal Processing ('Smart Innovation, Systems and Technologies' Series). In Proceedings of the International Workshop on New Approaches for Multidimensional Signal Processing 'NAMSP 2020', Sofia, Bulgaria, 9-11 July 2020; Kountchev, R., Mironov, R., Shengqing, L., Eds.; Springer: Berlin/Heidelberg, Germany, 2021; Volume 216, pp. 207-218.

51. Im, H.G.; Law, C.K.; Axelbaum, R.L. Opening of the Burke-Schumann Flame Tip and the Effects of Curvature on Diffusion Flame Extinction. Proc. Combust. Inst. 1991, 23, 551-558. [CrossRef]

52. Magina, N.; Steele, W.; Emerson, B.; Lieuwen, T. Spatio-temporal evolution of harmonic disturbances on laminar, non-premixed flames: Measurements and analysis. Combust. Flame 2017, 180, 262-275. [CrossRef]

53. Karimi, N. Response of a conical, laminar premixed flame to low amplitude acoustic forcing-A comparison between experiment and kinematic theories. Energy 2014, 78, 490-500. [CrossRef]

54. Kozlov, V.V.; Grek, G.R.; Korobeinichev, O.P.; Litvinenko, Y.A.; Shmakov, A.G. Combustion of hydrogen in round and plane microjets in transverse acoustic field at small Reynolds numbers as compared to propane combustion in the same conditions. Int. J. Hydrogen Energy 2016, 41, 20231-20239. [CrossRef]

55. Kashinath, K.; Waugh, I.C.; Juniper, M.P. Nonlinear self-excited thermoacoustic oscillations of a ducted premixed flame: Bifurcations and routes to chaos. J. Fluid Mech. 2014, 761, 399-430. [CrossRef]

56. Friedman, A.N.; Stoliarov, S.I. Acoustic extinction of laminar line flames. Fire Saf. J. 2017, 93, 102-113. [CrossRef]

57. Blaszczyk, J. Acoustically disturbed fuel droplet combustion. Fuel 1991, 70, 1023-1025. [CrossRef] 
58. McKinney, D.J.; Dunn-Rankin, D. Acoustically driven extinction in a droplet stream flame. Combust. Sci. Technol. 2007, 161, 27-48. [CrossRef]

59. Kornilov, V.N.; Schreel, K.; De Goey, L.P.H. Experimental assessment of the acoustic response of laminar premixed Bunsen flames. Proc. Combust. Inst. 2007, 31, 1239-1246. [CrossRef]

60. Rossi, L.; Akhloufi, M.; Tison, Y. On the use of stereovision to develop a novel instrumentation system to extract geometric fire fronts characteristics. Fire Saf. J. 2011, 46, 9-20. [CrossRef]

61. Madani, K.; Kachurka, V.; Sabourin, C.; Amarger, V.; Golovko, V.; Rossi, L. A human-like visual-attention-based artificial vision system for wildland firefighting assistance. Appl. Intell. 2017, 48, 2157-2179. [CrossRef]

62. Toulouse, T.; Rossi, L.; Campana, A.; Çelik, T.; Akhloufi, M. Computer vision for wildfire research: An evolving image dataset for processing and analysis. Fire Saf. J. 2017, 92, 188-194. [CrossRef]

63. Li, Z.; Mihaylova, L.S.; Isupova, O.; Rossi, L. Autonomous Flame Detection in Videos with a Dirichlet Process Gaussian Mixture Color Model. IEEE Trans. Ind. Inform. 2017, 14, 1146-1154. [CrossRef]

64. Toulouse, T.; Rossi, L.; Akhloufi, M.; Çelik, T.; Maldague, X. Benchmarking of wildland fire colour segmentation algorithms IET Image Process. 2015, 9, 1064-1072. [CrossRef]

65. Toulouse, T.; Rossi, L.; Çelik, T.; Akhloufi, M. Automatic fire pixel detection using image processing: A comparative analysis of rule-based and machine learning-based methods. Signal Image Video Process. 2016, 10, 647-654. [CrossRef]

66. Ivanov, S.; Stankov, S. The Analysis of Eco-Friendly Acoustic Firefighting and Systems for Fire Detection on the Basis of the Recent European Research. J. Commun. Softw. Syst. 2021. under review. 